\title{
ANALISIS PENDAPATAN DAN POLA KONSUMSI MASYARAKAT NELAYAN DESA ARAKAN KABUPATEN MINAHASA SELATAN
}

\author{
Jacline I. Sumual, Wensy F.I.Rompas, Steeva Y.L.Tumangkeng \\ Ekonomi Pembangunan-Fakultas Ekonomi dan Bisnis \\ Universitas Sam Ratulangi \\ Email : sumualjacline@gmail.com
}

\begin{abstract}
ABSTRAK
Tingkat pendapatan usaha penangkapan ikan secara tradisional relatif rendah. Rendahnya tingkat produksi tersebut disebabkan jangkauan daerah penangkapan ikan secara tradisional masih tergantung pada musim, maka pada saat-saat tertentu mengalami masa menganggur terutama pada musim hujan yang disertai dengan angin. Hal ini berarti jika pendapatan kurang akan membawa kemiskinan. Sampai saat ini belum dapat diidentifikasikan kegiatan nelayan pada musim tersebut, kalau tidak melaut berarti sejauh mana kemungkinan penciptaan kesempatan kerja yang sesuai agar nelayan dapat memperoleh pendapatan dimusim tidak kelaut. Tujuan yang akan di capai dalam penelitian ini adalah untuk mengetahui Bagaimana pendapatan nelayan di Desa Arakan Kabupaten Minahasa Selatan, Apakah usaha nelayan (menangkap ikan) mendapatkan keuntungan dan Bagaimana Pendapatan dan pola konsumsi masyarakat nelayan di Desa Arakan serta Pengaruh pendapatan terhadap Pola Konsumsi. Hal ini dimaksudkan untuk melihat dan mengevaluasi kebijakan dan bantuan pemerintah untuk meningkatkan kesejahteraan nelayan yang sampai sekarang di kategorikan masyarakat miskin .
\end{abstract}

Kata Kunci : Nelayan, Pendapatan, Konsumsi

\section{ABSTRACT}

The income level of fishing effort has traditionally been relatively low. The low level of production is due to the reach of traditional fishing areas still depend on the season, then at certain moments experienced spells of unemployment, especially in the rainy season, along with the wind. This means that if the income is less will bring poverty. Until now there has been an identifiable fishing activities on the season, if not to fish means the extent to which the possibility of the creation of appropriate employment opportunities so that fishermen can earn season is not the sea. Arakan villages with a population largely ethnic Bajo livelihood from fishing or fishing. However, some members of the public as well as farmers as a side job. The objective will be achieved in this research is to know how the income of fishermen in the village of Arakan South Minahasa regency Is fishing effort (fishing) benefit and How to consumption patterns in the fishing village of Arakan. It is intended to look at and evaluate policies and help the government to improve the welfare of fishermen that until now categorized poor.

Keywords: Fisherman, Income, Consumption 


\section{PENDAHULUAN}

Indonesia merupakan negara kepulauan terbesar di dunia terdiri dari gugusan pulaupulau sebanyak 17.508 dengan luas perairan laut Indonesia diperkirakan sebesar 5,8 juta km2 dan panjang garis pantai $95.181 \mathrm{~km}$, keadaan yang demikian menyebabkan Indonesia banyak memiliki potensi yang cukup besar di bidang perikanan, mulai dari prospek pasar baik dalam negeri maupun internasional.

Perikanan mempunyai peranan yang cukup penting dalam Pembangunan Nasional. Hal ini disebabkan karena adanya beberapa faktor, diantaranya adalah sekitar 2.274.629 orang nelayan menggantungkan hidupnya dari kegiatan usaha perikanan.

Kondisi kelompok masyarakat yang bermukim di wilayah pesisir dan pulau-pulau kecil yang berprofesi sebagai nelayan umumnya hidup dibawah garis kemiskinan,apakah hal ini disebabkan karena SDM dalam penguasaan teknologi perikanan dan sumber daya modal yang terbatas, sehingga sangat lambat dalam pengembangan usahanya. Selain hal tersebut sarana prasarana yang terbatas seperti pangkalan pendaratan ikan, sarana penngakapan, dan tempat penyimpanan ikan serta rendah kemampuan dalam pengelolaan sumberdaya alam adalah alasanalasan kemiskinan dan ketidak berdayaan.

Kondisi Sosial Ekonomi masyarakat nelayan di Desa Arakan ini sama halnya dengan kondisi masyarakat nelayan pada umumnya. Jika kondisi cuaca baik maka nelayan dapat pergi melaut setiap hari, hanya sebahagian nelayan saja yang memiliki pekerjaan sampingan .Di lain pihak mereka harus memenuhi kebutuhan hidup setiap hari.

\section{Pendapatan}

Pendapatan dari segi makro dapat dijelaskan dalam tiga pendekatan (Blanchard; 1997; Dornbusch and Fischer, 1997; Mankiw, G.N, 2000; Raharja dan Manurung, 2005),. Ketiga pendekatan tersebut meliputi pendekatan pengeluaran pendekatan penerimaan, dan pendekatan produksi.

Pendekatan pengeluaran adalah jumlah seluruh pengeluaran yang dilakukan oleh pelaku ekonomi yakni: konsumen, produsen, pemerintah dan luar negeri. Formula untuk pendekatan pengeluaran dapat ditulis yakni: $\mathrm{Y}=\mathrm{C}+\mathrm{I}+\mathrm{G}+\mathrm{X}-\mathrm{M}$; di mana $\mathrm{Y}$ adalah pendapatan nasional, $\mathrm{C}$ adalah konsumsi masyarakat, I adalah pengeluarag investasi, $\mathrm{G}$ adalah pengeluaran pemerintah, sedangkan $\mathrm{X}$ adalah nilai ekspor dan $\mathrm{M}$ adalah nilai impor.

Pendekatan penerimaan adalah jumlah balas jasa pemilik factor. Formulasi pendekatan penerimaan dapat ditulis yakni: $\mathrm{Y}=\mathrm{R}+(\mathrm{W}+\mathrm{S})+\mathrm{i}+\pi$; di mana $\mathrm{R}$ adalah rent sebagai balas jasa pemilik tanah, $\mathrm{W}+\mathrm{S}$ adalah wages and salaries sebagai balas jasa dari tenaga kerja, $i$ adalah interest sebagai balas jasa dari modal, dan $\pi$ adalah profit sebagai balas jasa dari skill atau manajerial/entrepreneurship. 
Pendekatan produksi adalah jumlah nilai produksi akhir dari barang dan jasa. Melalui pendekatan ini lebih mudah dihitung dengan pendekatan nilai tambah. Nilai tambah adalah nilai produksi dikurangi dengan intermediate cost.

\section{Pendapatan Masyarakat}

Dari pendekatan pendapatan secara makro sudut penerimaan maka dapat diaplikasikan pada pendapatan masyarakat. Komponen balas jasa faktor produksi tersebut yang meliputi rent, wages and salaries, interest, dan profit, dapat menjadi bagian dari masyarakat. Jika masyarakat sebagai pelaku usaha tani maka komponen pendapatan yang diperoleh meliputi keuntungan yang diformulasikan melalui pendekatan mikro ekonomi di mana keuntungan adalah revenue dikurangi ongkos produksi.

\section{Pengertian Produksi dan Fungsi Produksi}

Produksipengertian yang ilmiah seperti yang dikemukakan oleh Basu Swasta (1993 : 280) Sudarman (1994 : 199) menyatakan bahwa dalam beberapa buku teks ekonomi, produksi sering didefinisikan sebagai penciptaan guna, dimana guna berarti kemampuan barang dan jasa untuk memenuhi kebutuhan hidup manusia.

Smith dalam Rahmawati (1990), bahwa kemampuan nelayan untuk memaksimumkan hasil tangkapan ikan ditentukan oleh berbagai faktor anatara lain :

1. Modal kerja atau investasi adalah perahu/motor dan jenis alat tangkap.

2. Potensi Sumberdaya Perikanan/daerah operasi penangkapan ikan di laut.

3. Hari kerja Efektif melaut (HKE).

4. Kemudahan untuk memasarkan hasil tangkapan dengan harga yang wajar.

5. Biaya operasional/produksi antara lain : bahan bakar, perawatan alat tangkap dan biaya konsumsi waktu melaut.

Mubiyarto (1985) bahwa pendapatan seorang nelayan ditentukan oleh faktor produksi dan iklim atau musim.

Faktor-faktor lain yang mempengaruhi pendapatan nelayan adalah :

1. Modal investai,

2. Biaya operasional,

3. Pengalaman,

4. Tenaga kerja,

5. Musim,

6.

Keuntungan didefenisikan sebagai penghasilan/pendapatan berupa gaji/upah suatu arus uang yang diukur dalam waktu tertentu.Untuk mengetahui tingkat propabilitas digunakan untuk R/C (Revenue Cost Ratio) yaitu untuk perbandingan antara hasil dengan biaya total usaha nelayan. Semakin besar ratio tersebut berarti pengelolaan usaha nelayan semakin menguntungkan. 


\section{Harga dan Biaya}

Harga menurut Swasta Basu (1990 : 21) adalah sejumlah uang atau ditambah barang kalau mungkin yang dibutuhkan untuk mendapat sejumlah kombinasi dari barang beserta pelayanannya. Adapun tingkat harga dipengaruhi oleh beberapa faktor seperti kondisi perekonomian, penawaran dan permintaan, elastisitas permintaan, persaingan, biaya, tujuan manajer, pengawasan pemerintah.

Menurut Rahardja dan Manurung 2010:151 dalam buku Teori Ekonomi Mikro menyebutkan bahwa "laba atau keuntungan adalah nilai penerimaan total perusahaan dikurangi biaya total yang dikeluarkan perusahaan". Laba ditandakan dengan $\pi$, pendapatan total adalah TR, dan biaya total sama dengan TC. Maka fungsi dari laba adalah ( $\pi=$ TR-TC) Rahardja dan Manurung 2010:151 dalam Buku Toeri Ekonomi Mikro menambahkan bahwa "perusahaan dikatakan memperoleh laba kalau nilai $\pi$ positif $(\pi>0)$ dimana TR $>$ TC.Laba maksimun (maximum profit) tercapai bila nilai $\pi$ mencapai maksimum".Untuk mencari laba maksimun terdapat tiga pendekatan yang dapat digunakan, yaitu pendekatan totalitas (totality approach), rata-rata (average approach), dan marginal (marginal approach).

\section{Hubungan Modal Dengan Pendapatan Nelayan}

Menurut Case \& Fair dalam Prinsip-Prinsip Ekonomi (2007:268) menyebutkan bahwa "Modal ( Capital) adalah barang yang diproduksi oleh sistem ekonomi yang di gunakan sebagai input untuk memproduksi barang dan jasa di masa depan. Definisi modal tersebut terdiri dari dua jenis modal.Modal terbagi menjadi dua jenis yaitu modal berwujud dan modal tak berwujud."Modal tersebut merupakan modal yang digunakan dalam perusahaan.Modal berwujud adalah modal yang dapat dirasakan langsung dan modal tak berwujud di tentukan oleh setiap individu.

\section{Hubungan Harga Dengan Pendapatan Nelayan.}

Harga pada ikan yang ditawarkan oleh produsen kepada konsumen relatif stabil dan tidak mengalami kenaikan, artinya nelayan tidak mendapatkan untung lebih dari penjualan ikan tersebut. Hasil Tangkapan Nelayan Nelayan selalu mengharapkan hasil tangkapan ikan selalu mengalami peningkatan setiap harinya.Hal tersebut dapat menyebabkan pendapatan nelayan terus mengalami peningkapan.

\section{METODOLOGI PENELITIAN}

\section{Data dan Sumber Data}

Data yang digunakan dalam penelitian ini yakni data primer dan data sekunder. Data primer, yaitu data yang diperoleh langsung dari para nelayan yang ada di Desa Arakan Kabupaten Minahasa Selatan. Data sekunder, yaitu data yang diperoleh melalui pihak/instansi yang ada hubungannya dengan penelitian ini. 


\section{Metode Pengumpulan Data}

Dalam penelitian ini pengumpulan data dilakukan sebagai berikut :

1. Quisioner adalah berupa daftar pertanyaan tertutup untuk diisi oleh responden.

2. Wawancara adalah melakukan Tanya jawab dengan responden agar memperoleh data yang lebih akurat.

3. Observasi, yakni mendatangi langsung daerah / wilayah pemukiman nelayan yang ada di Desa Arakan Kabupaten Minahasa Selatan serta melakukan wawancara dan mengedarkan kuesioner.

\section{Metode Pengambilan Sampel}

Metode Pengambilan sampel yang digunakan dalam penelitian ini yakni Simple Random sampling yaitu pengambilan sampel responden secara acak sederhana. Untuk responden yang diambil sebagai sampel dalam penelitian ini adalah sebanyak 30 responden nelayan di ambil secara random.

\section{Metode Analisis Data}

\section{Analisis Tabel}

Analisis table digunakan untuk menjelaskan data umum responden, data pendapatan nelayan, biaya dan konsumsi.

2. Analisis BEP ( Break Event Point) dan analisis tingkat kelayakan usaha, digunakan untuk mengertahui layak tidaknya usaha penangkapan ikan oleh nelayan Desa Arakan Kabupaten Minahasa Selatan.

3. Analisis Regresi Linear Sederhanadigunakan untuk melihat pengaruh pendapatan terhadap Konsumsi Pangan dan non Pangan keluarga nelayan.

\section{HASIL DAN PEMBAHASAN PENDAPATAN DAN POLA KONSUMSI MASYARAKATNELAYAN DESA ARAKAN KABUPATEN MINAHASA SELATAN}

\section{Gambaran Wilayah Penelitian}

Desa Arakan merupakan desa Nelayan dengan Luas desa 18,2 Ha. 11,2 Ha merupakan pemukiman, dan 7 Ha merupakan hutan mangrove. Jumlah penduduk 1200 Jiwa, Jumlah Kepala keluarga 380 KK . Dari jumlak kepala keluarga sebanyak 380 KK yang ada di Desa Arakan, Masyarakat yang memiliki profesi sebagai nelayan sebanyak $300 \mathrm{KK}$, Petani $25 \mathrm{KK}$, Polisi/TNI 3 KK, PNS 2 KK, Swasta 20 KK, Pedagang 10 KK. 


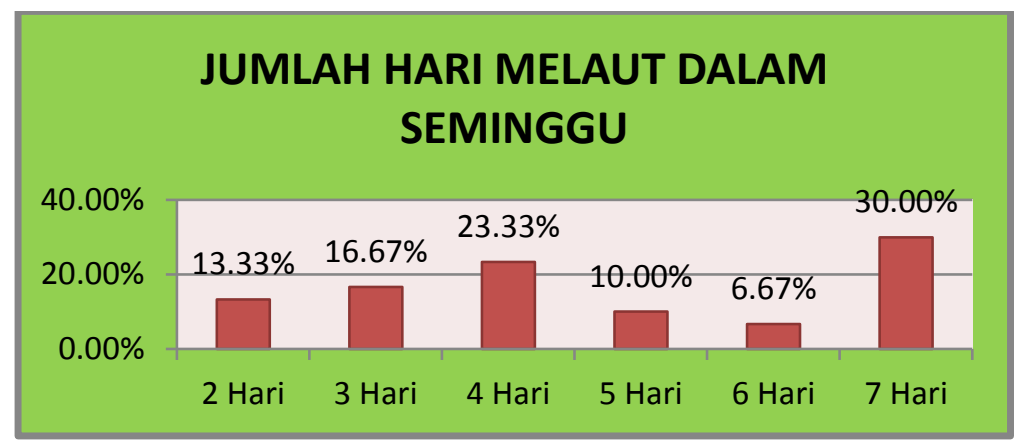

Sumber : Data diolah, 2016

\section{Gambar 1. Jumlah Hari Melaut Dalam Seminggu}

Jenis alat tangkap yang digunakan nelayan antara lain pukat, jubi dan jaring. Dari ketiga jenis alat tangkap ini jenis alat tangkap pukat paling banyak digunakan oleh nelayan yakni sebanyak $73,33 \%$ atau sebanyak 22 orang nelayan, sedangkan yang menggunakan jubi dan jarring masing - masing sebanyak 4 orang nelayan.

\section{Jumlah Produksi Ikan Laut}

Jumlah produksi ikan laut di pada nelayan sample di Desa Arakan seperti pada table di bawah ini :

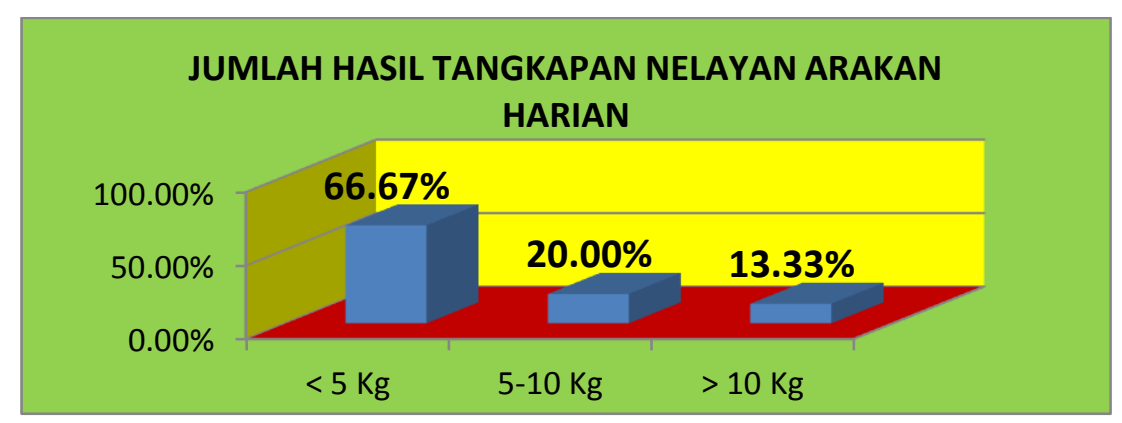

Sumber : Data diolah, 2016

\section{Gambar 2. Jumlah Hasil Tangkapan Nelayan Arakan Harian}

Dari table diatas dapat dilihat bahwa jumlah hasil tangkapan harian nelayan desa Arakan paling banyak dibawah $5 \mathrm{Kg}$, yaitu $66.67 \%$. Sedangkan jumlah hasil tangkapan bulanan dibawah $100 \mathrm{Kg}$ yaitu $66,67 \%$. 


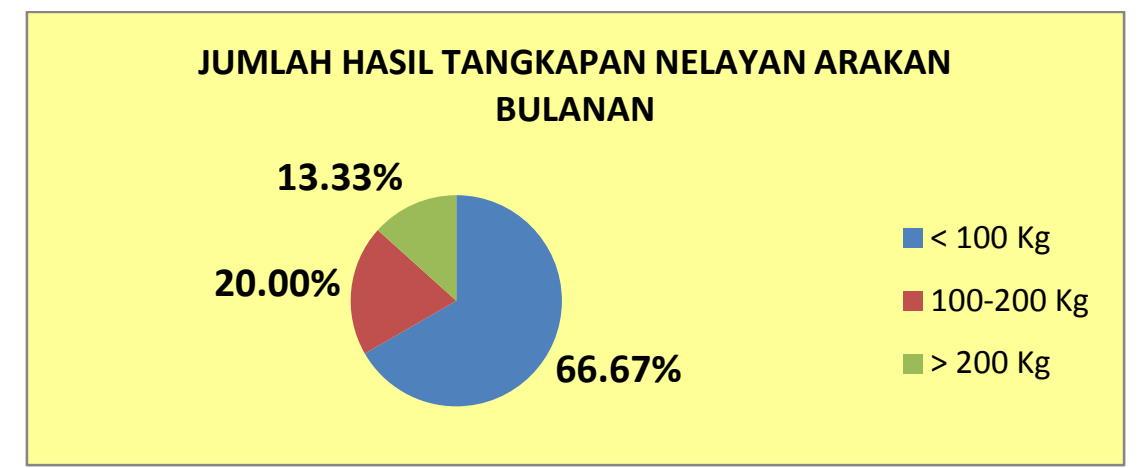

Sumber : Data diolah, 2016

Gambar 3. Jumlah Hasil Tangkapan Nelayan Arakan Bulanan

\section{Total pendapatan Keluarga, Pendapatan Nelayan Dari Hasil Melaut}

Berdasarkan data pendapatan nelayan dari hasil melaut dan pendapatan lainnya yang diperoleh nelayan dari pekerjaan sampingan menjadi petani maupun usaha sampingan lainnya maka total pendapatan nelayan diperoleh data sebagai berikut.

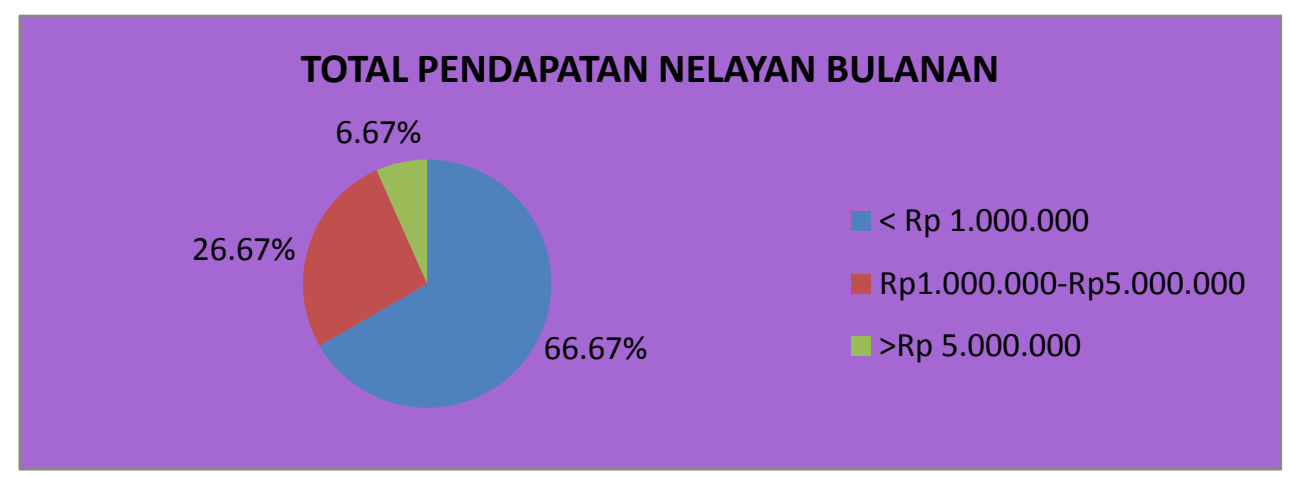

Sumber : Data diolah, 2016

Gambar 4.Total Pendapatan Nelayan Bulanan 
Jumlah Biaya Produksi Ikan Laut

Tabel 1. Rata - Rata Biaya Produksi Nelayan (Para Usaha Pengkapan Ikan Laut)

Dengan Berbagai Jenis Tangkapan

\begin{tabular}{|c|c|c|}
\hline Jenis Biaya & Biaya 1 Kali Melaut/ & $\begin{array}{c}\text { Biaya Per Bulan } \\
\text { (20 Kali Melaut) } \\
\text { Rp }\end{array}$ \\
\hline Biaya Tetap & 6.075 & 121.500 \\
\hline$-\underline{\text { Senar }}$ & 9.250 & 185.000 \\
$-\underline{\text { Gumala }}$ & 5.675 & 113.500 \\
$-\underline{\text { Goro Pentil }}$ & 4.175 & 83.500 \\
$-\underline{\text { Ladung }}$ & 13.575 & 271.500 \\
Biaya Variabel & 21.000 & 420.000 \\
\hline$-\underline{\text { Bensin }}$ & 10.000 & 200.000 \\
$-\underline{\text { Rokok }}$ & 10.000 & 200.000 \\
$-\underline{\text { Konsumsi }}$ & 10.000 & 200.000 \\
\hline Jumlah Biaya & & \\
\hline
\end{tabular}

Sumber : Data olahan Hasil penelitian, 2016

\section{Analisis BEP (Break Even Point) Pendapatan Usaha Penangkapan ikan}

Untuk Menganalisis Tingkat Produksi atau besarnya pendapatan sama dengan besarnya pengeluaran produksi ikan di desa Arakan digunakan metode analisis BEP (Break Even Point) (Soekartawati 1995 : 104).

Tabel 2.

BEP Produksi Ikan

\begin{tabular}{|c|l|r|}
\hline No & \multicolumn{1}{|c|}{ Uraian } & \multicolumn{2}{|c|}{ Total (Rp) } \\
\hline 1 & Total Biaya & 89.750 \\
\hline 2 & Price (harga jual) & 20.000 \\
\hline \multicolumn{2}{|c|}{ Nilai BEP Produksi } & 4 \\
\hline
\end{tabular}

Sumber : Data diolah, 2016

Tabel BEP produksi ikan diatas menunjukkan bahwa produksi ikan dilapangan adalah sejumlah $7>4 \mathrm{Kg}$, sehingga usaha ini telah melewati titik impas produksi (menguntungkan). 
Tabel. 3

BEP Harga Ikan

\begin{tabular}{|r|l|r|}
\hline No & \multicolumn{1}{|c|}{ Uraian } & \multicolumn{1}{|c|}{ Total (Rp/Kg) } \\
\hline 1 & Total Biaya & 89.750 \\
\hline 2 & Jumlah Hasil Produksi & 7 \\
\hline \multicolumn{2}{|c|}{ Nilai BEP Harga } & $\mathbf{1 2 . 8 2 1}$ \\
\hline
\end{tabular}

Sumber : Data diolah, 2016

Dari tabel BEP harga ikan diatas menunjukkan bahwa data di lapangan menunjukkan bahwa harga ikan Rp. $20.000>$ Rp. 12.821, sehingga usaha ini telah melewati titik impas harga (menguntungkan).

Dari tabel diatas menunjukkan bahwa hasil telah melewati nilai titik impas (BEP) baik Produksi maupun Harga dari usaha penangkapan ikan oleh masyarakat nelayan Desa Arakan hal ini menunjukan bahwa usaha penangkapan ikan oleh masyarakat menguntungkan.

\section{Analisis Pola Konsumsi Pangan dan Non Pangan Masyarakat Nelayan}

Berdasarkan data Pola konsumsi Pangan Dan non Pangan Masyarakat Nelayan di desa Arakan diperoleh hasil bahwa pola konsumsi bervariasi sesuai pendapatan nelayan. Alokasi engeluaran konsumsi paling besar untuk konsumsi non Pangan.

\section{Analisis Pengaruh Pendapatan terhadap Konsumsi Nelayan}

Berikut ini merupakan hasil olah data dengan menggunakan Eviews 8 untuk mengetahui pengaruh Pendapatan $(\mathrm{X})$ terhadap Konsumsi (Y). Hasil regresi tersebut dapat dilihat pada tabel di bawah ini berikut : $\mathrm{Y}=\mathrm{a}+\mathrm{bX}+\mathrm{e} \quad \mathrm{Y}=487466.4+0.345813 \mathrm{X}+0.157$

\begin{tabular}{|l|c|c|c|}
\hline \multicolumn{1}{|c|}{ Variabel } & Coefficient & t- statistic & Probabilitas \\
\hline Constanta & 487466.4 & 5.153731 & 0.0000 \\
\hline Pendapatan & 0.345813 & 12.24550 & 0.0000 \\
\hline $\mathrm{R}^{2}=0.843$ & \\
\hline
\end{tabular}

Sumber : Eviews 8

Dari persamaan di atas mengandung arti bahwa:

Nilai Koefisien regresi sebesar 0.345813 menunjukkan bahwa apabila terjadinya perubahan pendapatan sebesar Rp 1 juta yang diperoleh masyarakat Nelayan maka terjadinya kenaikan terhadap konsumsi masyarakat sebesar $\mathrm{Rp} 0.345813$. Nilai $\mathrm{R}^{2}$ yang diperoleh sebesar 0.843 artinya, variasi perubahan pendapatan mempengaruhi konsumsi sebesar $84.3 \%$, 
sedangkan sisanya (15.7\%) dijelaskan oleh variabel-variabel lain yang tidak dimasukan dalam model.

Hasil uji hipotesis diperoleh t-hitungsebesar $\mathrm{T}$ hitung sebesar 12.24550 dan $\mathrm{T}$ tabel $=1,699$ pada taraf signifikan 0,05 yaitu $n-d k=(30-1)=29$ yaitu 1,699. Dengan demikian dapat dijelaskan bahwa t-hitung lebih besar dari t-tabel yaitu $11.16151 \geq 1,699$ ( $\mathrm{T}$ hitung $\geq \mathrm{T}$ tabel) yang artinya dengan tingkat keyainan 95\%,uji signifikans menyatakan terdapat pengaruh tingkat pendapatan terhadap konsumsi

Sebagaimana hasil penelitian diperoleh bahwa tingkat konsumsi masyarakat nelayan Desa Arakan dipengaruhi oleh tingkat pendapatan.Secara umum dapat dijelaskan, apabila tingkat pendapatan masyarakat semakin meningkat maka semakin tinggi pula tingkat konsumsi.

\section{KESIMPULAN DAN SARAN}

Berdasarkan hasil penelitian sampai pada tahap sekarang maka dapat ditarik kesimpulan sebagai berikut :

\section{Kesimpulan}

1. Pendapatan Nelayan di Desa Arakan dari hasil melaut bervariasi sesuai banyaknya tangkapan ikan dari hasil melaut.

2. Sebahagian besar nelayan menggantungkan hidup dari hasil melaut, karena tidak memiliki pekerjaan sampingan.

3. Perahu dan Alat tangkap yang digunakan rata-rata menggunakan perahu kecil dengan kapasitas muatan sedikit, sehingga mempengaruhi jumlah tangkapan ikan.

4. Pola Konsumsi masyarakat Nelayan Desa Arakan bervariasi sesuai pendapatan

5. Pola konsumsi Masyarakat nelayan Desa Arakan paling besar dialokasikan untuk pengeluaran pangan sesudah itu untuk pengeluaran non Pangan

6. Berdasarkan hasil olah data statistic diperoleh hasil bahwa pendapatan mempengaruhi Konsumsi masyarakat nelayan di Desa Arakan Kabupaten Minahasa Selatan

7. Pendapatan Nelayan di Desa Arakan dari hasil melaut bervariasi sesuai banyaknya tangkapan ikan dari hasil melaut.

8. Sebahagian besar nelayan menggantungkan hidup dari hasil melaut, karena tidak memiliki pekerjaan sampingan.

9. Perahu dan Alat tangkap yang digunakan rata-rata menggunakan perahu kecil dengan kapasitas muatan sedikit, sehingga mempengaruhi jumlah tangkapan ikan.

\section{Saran}

- Para nelayan sebaiknya meningkatkan lagi teknologi dalam hal penangkapan ikan

- Meningkatkan pemasaran sehingga pendapatan dengan sendirinya akan naik.

- Meminta bantuan kepada pemerintah daerah agar bisa diberi pelatihan oleh tenaga tenaga ahli untuk meningkatkan teknologi penangkapan yang baik.

- Dapat mengajukan kredit pada pihak Perbankan atau Non Perbankan untuk meningkatkan hasil produksi bagi nelayan kecil. 


\section{DAFTAR PUSTAKA}

1) Astuti, Puji, 2007. Analisis Saluran Distribusi dan Pendapatan Nelayan Tambak Usaha Udang Windu di Desa Tasiwalie Kec. Suppa Kab. Pinrang. Universitas Hasanuddin

2) Dornbusch, Rudiger and Fischer Stanley (1997), Makro Ekonomi (terjemahan) oleh J Mulyadi. Judul Asli: Macroeconomics, Fourth Edition Penerbit Erlangga, Jakarta

3) http://www.google.co.id/ teknologi kelautan dan perikanan kabupaten mukomuko alat tangkap payang.htm. di akses 25 september 2011

4) Hanafiah, A.M dan Saefuddin. 2000. Tataniaga Hasil Perikanan UI, Press. Jakarta.

5) Kusnadi. 2000. Nelayan Strategi Adaptasi dan Jaringan Sosial. Humanoira Utama Press. Bandung

6) Mubiyarto. 1994. Ekonomi pertanian. LP3ES. Jakarta

7) Mankiw, Gregory N.(1992), Macroeconomics, Fourth Edition, Harvard University, New York

8) Nazir, Moh (1999), Metode Penelitian, Edisi Keempat, Ghalia Indonesia, Jakarta

9) Rahardja, Prathama dan Manurung, Mandala (2005), Teori Ekonomi Makro (suatu pengantar). Lembaga Peneribit FE-UI, Depok

10) Sugiyono. 2002. Statistika untuk Penelitian. CV Alfabeta. Bandung.

11) Soekartawi. 2003. Teori Ekonomi Produksi Analisis Fungsi Cobb-Douglas. Rajawali. Jakarta

12) Sukirno Sadono. 1999. Pengantar Teori Ekonomi Mikro, Edisi ke 2. PT Raja Grafindo Persada. Jakarta.

13) Suparmoko. 1997. Ekonomi Sumberdaya Alam Dan Lingkungan. Yogyakarta : BPFE.

14) Walangadi Hakop. 2003. Analisis Factor-Faktor Yang Mempengaruhi Produksi Ikan Di Propinsi Gorontalo Thesis Program Pasca Sarjana Universitas Hasanuddin. Makassar. 